European Journal of Social Psychology

Eur. J. Soc. Psychol. 38, 1044-1053 (2008)

Published online 14 January 2008 in Wiley InterScience

(www.interscience.wiley.com) DOI: 10.1002/ejsp.490

\title{
Solo status and women's spatial test performance: The role of individuation tendencies
}

\author{
JOHANNES KELLER ${ }^{1,2 *}$ AND DENISE SEKAQUAPTEWA ${ }^{1}$ \\ ${ }^{1}$ University of Michigan, USA \\ ${ }^{2}$ University of Mannheim, Germany
}

\section{Abstract}

The impact of anticipated solo status on women's spatial performance was investigated in an experimental study. The study was designed to test whether the underperformance of women entering testing situations who find themselves to be the only woman present is related to a tendency to individuate the self. Women performed a test of spatial ability under conditions of anticipated solo or non-solo status and responded to a measure of self-construal. In line with previous research, we found a disrupting solo status effect on women's performance on the spatial ability test. Most importantly, the negative effect of solo status on performance was partially mediated by individuation tendencies as reflected in a decreased predominance of the interdependent (as compared to the independent) level of the self under solo status conditions. These findings indicate that individuation tendencies play a crucial role in the process triggered in test takers under threatening performance situations. Copyright (C) 2008 John Wiley \& Sons, Ltd.

Women studying or working in domains non-traditional for women, such as engineering, math and sciences, likely face not only negative stereotypes about women's ability in these areas but also a lack of female colleagues (National Science Foundation, 1996). A substantial body of research documents that the perceived relevance of stereotypes and the gender composition of one's immediate environment are subtle cues that can have a profound effect on performance outcomes (Steele, Spencer, \& Aronson, 2002). In the present study, we examine whether solo status - defined as being the only member of one's social category in an otherwise homogeneous group (Lord \& Saenz, 1985; Sekaquaptewa \& Thompson, 2002) - has the potential to affect women's performance on a spatial ability test. Extending previous research documenting the detrimental effects of solo status on performance (Sekaquaptewa \& Thompson, 2002, 2003; Sekaquaptewa, Waldman, \& Thompson, 2007), this research begins to explore the underlying mechanisms of this effect, focusing on individuation tendencies as reflected in an independent over an interdependent self-construal orientation.

\section{THREATENING PERFORMANCE SITUATIONS}

When test takers are aware that their group is negatively stereotyped in terms of ability in the domain (e.g., "women can't do math"), and that their behavior may be perceived in terms of that stereotype, a group-based threat can arise. For example, women taking math tests said to be diagnostic of their math ability may perceive that a poor performance would seem stereotype-confirming (Spencer, Steele, \& Quinn, 1999). The fear of being seen as confirming negative stereotypic expectancies has been termed stereotype threat and a large body of research has documented the detrimental effects of stereotype threat on test performance (Steele et al., 2002).

In addition to the perceived relevance of stereotypes in a testing situation, environments in which one's gender or race is not well represented also serve as source of concerns about being categorized or perceived in terms of stereotypes

*Correspondence to: Johannes Keller, Universität Mannheim, Lehrstuhl für Mikrosoziologie \& Sozialpsychologie, 68131 Mannheim, Germany.

E-mail: jkeller@uni-mannheim.de 
(Murphy, Steele, \& Gross, 2007; Purdie-Vaughns, Steele, Davies, Ditlmann, \& Crosby, 2006; Sekaquaptewa \& Thompson, 2002). This research shows that underperformance effects similar to those documented in stereotype threat research can emerge when test takers experience gender or racial solo status (i.e., when they are the only woman or racial minority group member in the testing group), even when the testing domain is not one in which the test taker's group is negatively stereotyped (e.g., when the test topic is the social behavior of animals; Sekaquaptewa \& Thompson, 2002). Thus, it appears that two related but distinct sources of threat can have important and dual impacts on the performance of women testing in domains in which women are negatively stereotyped and under-represented.

Although the detrimental effects of both types of threat are well documented, less is known about the underlying mechanisms (Wheeler \& Petty, 2001). Some recent evidence points to a mediating role of mental load (Croizet, Després, Gauzins, Huguet, Leyens, \& Méot, 2004; Schmader \& Johns, 2003). For example, using a dual task paradigm Schmader and Johns (2003) documented that working memory capacity is reduced under conditions of stereotype threat, and that this reduction in working memory capacity mediates the effects of stereotype threat on test performance. These findings represent significant progress toward the understanding of the underlying mechanisms involved in stereotype threat effects on performance. However, it is still unclear exactly what triggers the observed disruptive mental load. It may be that activation of distracting thoughts related to the respective negative stereotype leads to the reduction of cognitive resources (e.g., Cadinu, Maass, Rosabianca, \& Kiesner, 2005; Davies, Spencer, Quinn, \& Gerhardstein, 2002; Quinn \& Spencer, 2001). Or perhaps a heightened level of worry, associated (physiological) arousal, and related defensive mechanisms (such as self-handicapping) may be responsible, as threat elicits defensive concerns and related motivational and strategic mechanisms that are closely associated with (physiological) arousal processes (Ben-Zeev, Fein, \& Inzlicht, 2005; Blascovich, Spencer, Quinn, \& Steele, 2001; Keller, 2002, 2006, 2007; Keller \& Bless, in press-a, in press-b; Marx \& Stapel, 2006; Murphy et al., 2007; O’Brien \& Crandall, 2003; Stone, 2002). It seems likely that women's performance under threat is influenced by a variety of processes that may fall into either category or even somewhere in between.

The present study addresses one specific mechanism that can be interpreted as strategic self-management and thus reflects a more motivational or strategic type of process. Specifically, we tested whether identity management in terms of a tendency to individuate the self is activated for women under threat, and contributes to women's performance decrements under threatening conditions. Such tendencies may be protective, as they serve to distance the self from the social identity that is stigmatized in the situation (Steele \& Aronson, 1995).

\section{Self-construal Mechanisms Under Threat}

In testing the role of individuation tendencies under threat, we refer to a conceptualization of the self-concept that differentiates two basic dimensions of the self: the independent and interdependent self (Brewer \& Gardner, 1996; Markus \& Kitayama, 1991). According to this perspective, the independent self reflects thinking of oneself as distinct from others, emphasizing a clear boundary separating the self from others. In contrast, the interdependent self reflects thinking of oneself in terms of social relationships or collectives with an emphasis on closeness and relatedness. Although these self-construals are sometimes seen as opposites, it may be more accurate to conceptualize them as largely distinct or independent aspects of the self. This perspective is supported by research showing that scales designed to assess both dimensions of self-construal (Singelis, 1994) were either largely uncorrelated (e.g., Kemmelmeier \& Oyserman, 2001; Sato \& Cameron, 1999; Singelis, 1994) or slightly positively correlated (Bresnahan, Levine, Shearman, Lee, Park, \& Kiyomiya, 2005; Grace \& Cramer, 2003).

We utilize the self-construal concept in order to assess whether gender-based threats elicit a tendency to individuate the self, such that women emphasize the independent self under conditions of a gender-based threat. In support of this idea, some previous research documents a heightened tendency to distance the self from the relevant group under threatening conditions, indicating a desire to individuate the self. In one study (Steele \& Aronson, 1995, Exp. 3) African-American test takers provided self-descriptions that were significantly less stereotypic under conditions of stereotype threat compared to no threat conditions. Similarly, Pronin, Steele, \& Ross (2004) found that math-identified women reported significantly lower identification with feminine characteristics under conditions of stereotype threat as compared to no threat conditions. Cohen and Garcia (2005) showed that collective stereotype threat (the concern that in-group members might engage in stereotype-confirming acts) resulted in a tendency to physically distance the self from in-group members and to rate traits and behaviors that are stereotypically associated with the relevant in-group as less self-descriptive. Moreover, Huguet and Régner (2007) observed that the accessibility of positive in-group role models (high-math-ability girls, i.e., in-group-related 
knowledge) was diminished under conditions of stereotype threat. Finally, additional research indicates that the activation or affirmation of the individual self can buffer against the detrimental effects of stereotype threat on performance (Ambady, Paik, Steele, Owen-Smith, \& Mitchell, 2004; Martens, Johns, Greenberg, \& Schimel, 2006). In sum, these findings indicate that test conditions involving a gender-based threat may activate a tendency to distance the self from the group and that activating the accessibility of the individual self in test takers may serve a protective function.

On the other hand, we note that some findings obtained in research on group-based threats to performance seem incompatible with the individuation assumption outlined above. Some research has revealed that the experience of gender stereotype threat can trigger an enhanced accessibility of the collective self among women-as assessed with a pronoun guessing task (Marx, Stapel, \& Muller, 2005; Exp 1), a self-group overlap measure, and a group identification measure (Marx et al., 2005; Exp. 2). Moreover, the experimental activation of the collective self via a "we"-priming procedure (Brewer \& Gardner, 1996) diminished women's math test performance compared to an individuation prime (Keller \& Molix, in press) or a no self-prime control condition (Marx \& Stapel, 2006). Finally, in the domain of racial solo status, African-American women expecting to join an all-White testing group reported stronger racial identification than a control group (Sekaquaptewa et al., 2007). In combination, these results suggest that the collective self is involved in the process resulting in disrupted performance under threatening test conditions.

In review, it may seem that the two mechanisms - activation of the collective self and enhanced group identification on the one hand and activation of individuation tendencies and distancing from the group on the other-are incompatible. However, we suggest that the activation of the collective self may be understood as a defining but only partial component of self-related processes under threat. That is, the enhanced accessibility of the collective self may only be one specific aspect of self-related mechanisms under threat and may even reflect a necessary ingredient of individuation processes, as distancing the self from a group may require the activation of group-related knowledge. Subsequently (or simultaneously) to the activation of group-related knowledge, motivated mechanisms set in that reflect a protective orientation of self-regulation. In other words, the concept of the group must be activated if distancing from the group is to occur. Accordingly, we see the two mechanisms not as incompatible but rather reflecting two complementary self-related aspects that can both be involved in the processes triggered under threat.

\section{Individuation as Underlying Mechanism of Solo Status Effects on Performance}

The basic theoretical assumption underlying the present research holds that one way of coping with gender-based threat experiences is to engage in individuation in order to distance the self from a social identification that is associated with negative aspects - a strategy that has been (indirectly) documented in previous research (e.g., Cohen \& Garcia, 2005; Pronin et al., 2004; Steele \& Aronson, 1995). Specifically, we propose that the self-construal orientation of female test takers changes under threat such that greater emphasis is placed on the independent (vs. interdependent) level of the self. Accordingly, we hypothesize that solo status diminishes spatial ability test performance among women and that this effect is (at least partially) mediated via self-construal mechanisms reflecting these individuation tendencies. ${ }^{1}$

\section{METHOD}

\section{Overview}

Female participants were told they would work on a spatial ability puzzle in front of a group that would evaluate their performance. Solo and non-solo conditions were created by showing participants biographical forms indicating gender

\footnotetext{
${ }^{1}$ Although we do not empirically address the specific mechanisms that are likely to be associated with individuation tendencies and represent more proximate mediator variables, we want to outline the possible causal path leading from solo status to decreased performance. We propose that individuation tendencies reflect an increased level of self-focused attention-the awareness that one's actions may affect others' impressions of oneself (i.e., a public self-focus; cf. Carver \& Scheier, 1987). Given that public self-focused attention is well known to be related to anxiety (and negative affect in general; cf. Mor \& Winquist, 2002), we argue that the increased level of self-focused attention under solo status conditions is likely to be related to increased levels of anxious arousal (and related worries) which is known to contribute to decreased performance levels (cf. Eysenck \& Calvo, 1992). In combination with research documenting detrimental effects of anxiety and related worries on working memory capacity (cf. Darke, 1988), these lines of research suggest that working memory capacity is probably the most proximate mediator of the effects of threatening environments on test performance and this has been supported in recent studies (cf. Beilock, Rydell, \& McConnell, 2007; Schmader \& Johns, 2003).
} 
ostensibly completed by the anticipated group, coupled with videotaped footage showing that the group was either all male (solo condition) or all female (non-solo condition). Participants then completed a written spatial ability test alone while expecting to join the all male or all female group. A measure of interdependence/independence was administered after the solo status manipulation but prior to the written spatial ability test, the primary dependent measure.

\section{Participants}

Female psychology students $(N=71)$ participated in partial fulfillment of their course requirements. Seven participants were dropped due to procedural error, leaving a final sample of 64 women (51 White, 10 Asian American, 3 African American; note that participant race did not affect the results reported below) who were randomly assigned to either the solo or non-solo condition.

\section{Materials and Procedure}

Upon arrival at the laboratory, participants were seated in a private cubicle. Each cubicle contained questionnaires and experiment information, a headset, and a television monitor on top of which a camera was mounted. Experimental sessions included from one to four participants.

Participants heard instructions over the headsets from the experimenter seated in an adjacent control room. The experimenter briefly explained the general experimental procedure, then instructed participants to open an envelope containing instructions that conveyed the cover story: that the experiment involved comparisons of private and public performance on spatial ability tasks. Participants would first complete a standard paper-and-pencil spatial ability test in their cubicles; a sample item was given. Afterwards, participants would be taken individually to join a group (termed the "testing group") in a larger room and complete a spatial ability task described as the physical version of the paper-andpencil problems, i.e., a folding block puzzle. Participants were told they would be allowed 2 minutes to work on the folding block puzzle in front of the testing group, after which the testing group would rate their performance.

It was further explained that performance in group settings may be influenced by how familiar people are with their group members; therefore, in half of the experimental sessions participants and their testing groups would be allowed to exchange some brief biographical information, and see closed circuit television footage of one another prior to meeting. Participants learned that their session had been randomly assigned to the condition in which they would exchange information and see each other prior to meeting.

Participants then completed a short biographical form (including first name, major, and hobbies/interests), with the understanding that the three members of the testing group were completing the same form. The experimenter then showed the participant three biographical forms ostensibly completed by members of the testing group. The forms were pre-written to reflect that the testing group was either all male (solo condition) or all female (non-solo condition), via the first names used (e.g., Stephanie, Steve) and the gender-stereotypic hobbies listed (e.g., ballet, football). The experimenter collected the participant's form, and asked her to read the forms of the testing group members. The experimenter repeated the process with the remaining participants in their cubicles.

Afterwards the experimenter announced over the headsets that the closed circuit television system would now be activated. It was explained that first a camera would be activated on the testing group, and each participant would see the testing group briefly on her cubicle monitor. The experimenter then played pre-recorded videotaped footage showing either three male (solo condition) or three female (non-solo condition) confederates seated around a table (no testing group was actually present during experimental sessions). The gender of the experimenter and that of the testing group shown always matched. The videotaped footage lasted 8 seconds, and confederates did not talk and made only incidental movements.

Next, it was explained that the experimenter would activate the camera located in each participant's cubicle one by one, which would allow the testing group to see each participant briefly on their testing group monitor. Participants were told that when the identifying codename of each cubicle (posted inside the cubicle) was announced, the camera in that cubicle would be activated (indicated by a red light being illuminated on the camera). It was explained that the camera would be activated for 5 seconds, during which time they would not need to say or do anything; and when the red light turned off, 
the camera was deactivated. Over the headsets, the experimenter then announced the cubicle codenames in turn. Participants were unaware that every cubicle was actually labeled with the same codename, and thus believed that only their camera was activated when their codename was called. In actuality, the experimenter simply called extraneous cubicle codenames without activating any cameras, then called the cubicle codename given to each participant, pressing a button that illuminated the red indicator light in all cubicles for 5 seconds. With the exception of the indicator light, the cubicle cameras were non-functional. In this way, participants believed that the camera relayed footage of themselves to the testing group's monitor, although no camera footage was actually recorded.

After each participant received the solo status manipulation, she was asked to complete a questionnaire prior to joining the testing group. The questionnaire contained filler questions plus two questions assessing concern about being gender stereotyped which were used as a solo status manipulation check ("I am concerned that if I don't do well on the spatial ability tests it will look stereotypic of my gender," and "I am concerned that people will judge my gender as a whole based on my spatial ability performance," answered on a 1-7 scale, strongly disagree to strongly agree). The questionnaire also included the 24-item self-construal scale (Singelis, 1994), which included 12 statements about collectivism and 12 about individualism (e.g., "I will sacrifice my self-interest for the benefit of a group I am in" and "I enjoy being unique and different from others in many respects," respectively). The participants rated their agreement with the statements on a 1-7 scale (not true to very true). ${ }^{2}$

Next, participants were instructed to begin working on the spatial ability test, a 20-item, multiple-choice subtest of an intelligence test (Jäger \& Althoff, 1983) consisting of figure-folding test items. Each item consisted of an unfolded model figure (e.g., a cube) with lines, dots, or other markings on some parts of the surface, and five answer figures, one of which could be created by folding the model figure. Participants were asked to select the one figure identical to the unfolded model figure. Substantial gender differences typically emerge on this test (cf. Jäger \& Althoff, 1983). Participants were given 5 minutes to work on the test.

Participants then completed a final questionnaire before they were to be taken one by one to complete the folding block puzzle in front of the testing group. The questionnaire included filler items and two spatial ability skills self-ratings ("I am usually good at spatial skills," and "I consider myself to have strong spatial ability skills," rated on a 1-7 scale, strongly disagree to strongly agree). Afterwards, the experimenter gather all participants from their cubicles and brought them into the control room, where they were told the experiment was over, probed for suspicion and fully debriefed.

\section{RESULTS}

\section{Manipulation Check}

Ratings of the two gender stereotyping concern items were positively correlated, $r(64)=.75, p<.001$, and the items were averaged to form a composite score. Results of ANOVA showed that gender stereotyping concerns were significantly higher in the solo $(M=4.03)$ than in the non-solo $(M=2.50)$ condition, $F(1,62)=10.59, p<.01$, Cohen's $d=0.82$. Thus, the solo status manipulation appeared to be effective and powerful in producing concern among women about being perceived in terms of gender.

\section{Self-construal}

To assess effects on the level of self-construal, a difference score was created, subtracting the average rating of the eight individualism questions $(M=4.51, \mathrm{SD}=0.83$, Cronbach's alpha $=.69)$ from the average rating of the 10 collectivism

\footnotetext{
${ }^{2}$ We conducted principal components analyses with varimax rotation (imposing a two-dimensional solution) and found that all but four items showed loadings $(\geq .25)$ on the respective components. Among the remaining 20 items, two had high factor loadings on the component they should not be associated with a priori according to the theoretical framework. When we deleted the six problematic items, an additional analysis revealed a clear two-dimensional structure such that all of the 18 items ( 10 items for the interdependence subscale eight items for the independence subscale) showed the expected substantial loadings on the relevant component. Three items showed secondary loadings. However, given that these items showed substantial item total correlations $(\geq .33)$ with the scales they are associated with a priori according to the theoretical framework, we retained these items in the respective scales.
} 


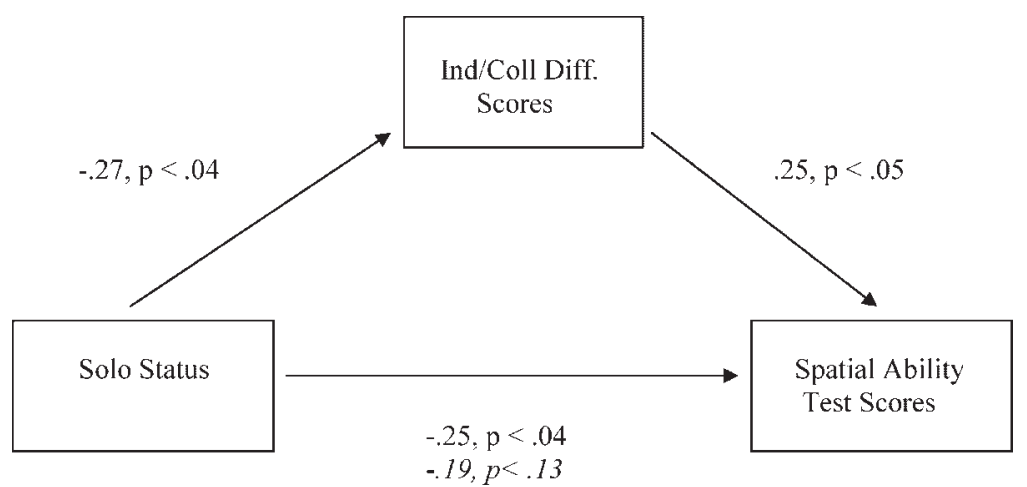

Figure 1. Test of mediation (collectivism-individualism difference scores) of solo status on spatial ability test scores

questions $(M=4.76, \mathrm{SD}=0.72$, Cronbach's alpha $=.72)$. This score indicates whether self-construal is predominantly interdependent (positive values) or predominantly independent (negative values). Because there does not appear to be any clear-cut theoretical reason to assume that only one self-construal dimension, either independence or interdependence, is exclusively affected by solo status, we examine the two dimensions in a comparative sense, i.e., in terms of level of independence compared to level of interdependence. Collectivism-individualism difference scores ranged from -2.65 to 2.13, $M=0.25, \mathrm{SD}=0.93$. Higher scores indicated greater collectivist than individualist self-construal.

Results of ANOVA showed a significant effect of condition, $F(1,62)=4.92, p<.04$, such that collectivismindividualism difference scores were reduced in the solo $(M=-0.03)$ compared to the non-solo condition $(M=0.49$; Cohen's $d=0.56$ ). Analyses of individualism and collectivism scores separately indicated that collectivism scores tended to be lower in the solo $(M=4.64)$ than the non-solo $(M=4.94)$ condition, $F(1,62)=2.80, p<.10$, Cohen's $d=0.42$, whereas individualism scores were not significantly different in the solo $(M=4.68)$ and the non-solo $(M=4.45)$ conditions, $F(1,62)=1.27, p=.27$, Cohen's $d=0.28$.

\section{Spatial Ability Test}

One point was given for each correct answer on the spatial ability test and these points were summed to form a total score (points were not subtracted for wrong answers). Spatial ability test scores (overall $M=7.14, \mathrm{SD}=2.71$ ) were analyzed with ANCOVA, using the average of the two self-reported spatial ability skills items as a covariate ${ }^{3} F(1,61)=7.68$, $p<.01$. Results showed a significant effect of condition, $F(1,61)=4.52, p<.04$, such that spatial ability test scores were reduced in the solo $(M=6.53)$ compared to the non-solo condition $(M=7.68)$. The effect size estimate (Cohen's $d=0.43)$ revealed that this is a noticeable effect. ${ }^{4}$

The potential of self-construal to mediate the effect of solo status on spatial ability performance was tested following the procedure described by Baron and Kenny (1986) using three regression analyses. The first regressed spatial ability test scores on self-rated spatial ability skills (covariate) and solo status condition; the second regressed collectivis$\mathrm{m}$-individualism difference scores on these same factors; and the third regressed spatial ability test scores on these same factors including collectivism-individualism difference scores in the model (see Figure 1). Results showed that solo status condition was a significant predictor of collectivism-individualism difference scores, and collectivism-individualism difference scores were significantly related to spatial ability test scores. When collectivism-individualism difference

\footnotetext{
${ }^{3}$ Responses on the covariate (self-reported spatial ability level) were not influenced by the solo status manipulation and did not differ by participant race, $F_{\mathrm{s}}<1$. Note that mean scores on the ability self-ratings were actually slightly higher in the solo status condition $(M=3.25)$ compared to the non-solo condition $(M=2.96)$.

${ }^{4}$ A simple one-way analysis of variance (ignoring participants' spatial ability self-ratings) revealed that the effect of the solo status manipulation on test performance was marginally significant, $F(1,62)=2.93, p<.10$. Given that scores on the ability self-ratings were slightly higher in the solo status condition compared to the non-solo condition (see Footnote 4) and accordingly there is reason to assume that participants in the solo condition had a slightly higher baseline ability level than their non-solo counterparts, it seems remarkable that the solo status manipulation effect on performance is detectable even when participants' ability self-ratings are not taken into account. Moreover, the observed effect size also speaks to the fact that the solo status manipulation was quite powerful.
} 
scores were not included in the model, solo status significantly predicted spatial ability test scores. But when collectivismindividualism difference scores were included in the model, the relationship between solo status and spatial ability test scores was no longer significant. These results provide evidence that self-construal does play a mediating role regarding the effects of solo status on spatial ability test performance, such that women become less collectivistic than individualistic when anticipating solo status, and their lower relative collectivism in turn lowers their spatial ability test scores.

The significance of the mediated effect was assessed using a procedure that tests for a significant change in the beta coefficient in the comparison of regression models (Clogg, Petkova, \& Haritou, 1995). ${ }^{5}$ Results indicated that the reduction of the path from the solo status manipulation to test performance was significant, $t(60)=2.01, p<.05$.

\section{DISCUSSION}

The obtained findings support the proposed mediation hypothesis: the impact of the solo status on participants' test performance was partially mediated by individuation tendencies. This adds to previous results documenting detrimental effects of threatening environments on women's spatial performance (cf. Huguet \& Régner, 2007; McGlone \& Aronson, 2006; Moè \& Pazzaglia, 2007; Sharps, Welton, \& Price, 1993) and to previous work indicating that identity threat can result in disidentification and distancing from the relevant in-group (cf. Cohen \& Garcia, 2005; Pronin et al., 2004; Steele $\&$ Aronson, 1995). Thus, these findings document a crucial underlying mechanism that is involved in solo status effects on test performance.

Three aspects of the present study are particularly noteworthy. First, the study represents the first direct empirical test of the mediating role of individuation tendencies regarding the effects of group-based threat effects on test performance. Neither Steele and Aronson's (Steele \& Aronson, 1995; Exp. 3) nor Pronin et al.'s (2004) studies included a test of cognitive ability or a measure of self-construal. Second, by using a new manipulation of solo status (in which participants anticipated being a solo in a testing group), we demonstrated that the solo status effect is powerful even in an anticipatory setting. Third, we designed a replication of solo status effects using a test of spatial ability (rather than an academic or math test as in previous research), which speaks to the generalizability of the phenomenon.

The current findings are consistent with the perspective that individuation may be a protective strategy that serves to distance the self from a social identity that is devalued in the situation (cf. Cohen \& Garcia, 2005; Pronin et al., 2004; Steele \& Aronson, 1995). Of interest, other findings have indicated the opposite. For example, Marx et al. (2005, Exp. 2) observed increased gender group identification under conditions of threat. In this article, we proposed that both mechanisms (enhanced accessibility of the social self and increased individuation tendencies) reflect two complementary self-related processes that can both be triggered under threat. It seems likely that threatening performance situations can make group memberships salient and under some circumstances psychological distancing from the now-salient group may occur as a self-protective strategy. Thus, it becomes important to identify the circumstances under which threatening performance situations lead to group identification, group distancing, or both.

It seems likely that individuals' self-construal and identity mechanisms may be affected in different ways depending on the type (or source) of threat experienced, as well as the specific social identity (e.g., race, gender, social class) under threat. For example, manipulating threat by way of describing a test as diagnostic of a certain ability (or not) is most likely related to different concerns in the test takers (under threat and no threat conditions) than it is the case when threat is manipulated based on a fairness manipulation (i.e., by describing a test as gender-fair or gender-biased) or by the gender composition of the group of test takers. In the former case (diagnosticity manipulation), identity concerns seem somewhat less salient than in studies using fairness or solo status manipulations (for a similar perspective, see Brown \& Pinel, 2003).

Self-construal may also be influenced differently depending on the particular social identity under threat, due to differences in perceived meaning or breadth of the threat to that social identity. For example, gender stereotypes about ability tend to be focused in specific performance domains ("women have poorer spatial ability skills than men"), whereas some racial stereotypes may be generalized across domains ("African Americans are poorer students than Whites"). Indeed, previous analyses of workplace personnel has shown that in regards to numerical under-representation,

\footnotetext{
${ }^{5}$ As MacKinnon, Lockwood, Hoffman, West \& Sheets (2002) noted, the most widely used Sobel test approach to testing for mediation has low statistical power and these authors discussed several alternative procedures that can be applied. One alternative type of analysis is the one introduced by Clogg et al. (1995) as applied in the present case.
} 
detrimental effects on women are apparent until the representation of women equals that of men (50:50 gender ratio), whereas African Americans experience detrimental effects at all levels of representation except for the case where African Americans very strongly outnumber Whites (90:10 Black to White ratio; Sackett, DuBois, \& Noe, 1991). This suggests that some social identifications may be perceived as particularly global and meaningful, and thus, once activated, may be less amenable to distancing under threat. In sum, future research should investigate these and other potentially important factors (e.g., perceived permeability of the social identity) to help identify when threatening performance situations will lead one to embrace and/or distance oneself from the threatened social identity.

Although the present study provided useful information regarding individuation mechanisms under solo status conditions, it is important to note its limitations. First, we did not assess variables that supposedly are related to individuation tendencies (e.g., self-focused attention, anxiety, or working memory capacity, see Footnote 1). Thus, we cannot address the more proximate underlying mechanisms that are likely to contribute to performance decrements under solo status conditions. Second, only women participated in the current study. Future studies should also include men in order to understand whether the observed effects are gendered in nature. Third, our data suggest that the manipulation affected interdependence scores somewhat stronger than independence scores. However, the effect of the solo status manipulation was not significant in the analysis using interdependence scale scores alone. Thus, we may only conclude that women became relatively less interdependent in their self-construal under solo status conditions (as reflected in a slightly stronger endorsement of statements related to independent self-construal as compared to statements related to interdependent self-construal under solo status conditions).

These limitations notwithstanding, the present research and observed findings contribute to understanding of the role that self-construal mechanisms play concerning solo status effects on test performance. The current study documented that individuation mechanisms contribute to the disrupting effects of anticipating solo status in a test performance context. As such, the current study opens a new avenue of research for studying mechanisms involved in group-based threat effects on test performance that incorporates the crucial impact of self-construal mechanisms.

\section{ACKNOWLEDGEMENTS}

This research was supported by a post-doctoral grant from the German Science Foundation to Johannes Keller, who worked at the Institute for Social Research, University of Michigan, during preparation of this article. We are grateful to Emily Chapin and John Barrett for their help in data collection.

\section{REFERENCES}

Ambady, N., Paik, S. K., Steele, J., Owen-Smith, A., \& Mitchell, J. P. (2004). Deflecting negative self-relevant stereotype activation: The effects of individuation. Journal of Experimental Social Psychology, 40, 401-408.

Baron, R. M., \& Kenny, D. A. (1986). The moderator-mediator variable distinction in social psychological research: Conceptual, strategic, and statistical considerations. Journal of Personality \& Social Psychology, 51, 1173-1182.

Beilock, S. L., Rydell, R. J., \& McConnell, A. R. (2007). Stereotype threat and working memory: Mechanisms, alleviation, and spillover. Journal of Experimental Psychology: General, 136, 256-276.

Ben-Zeev, T., Fein, S., \& Inzlicht, M. (2005). Arousal and stereotype threat. Journal of Experimental Social Psychology, 41, $174-181$.

Blascovich, J., Spencer, S. J., Quinn, D. M., \& Steele, C. M. (2001). Stereotype threat and the cardiovascular reactivity of African-Americans. Psychological Science, 12, 225-229.

Bresnahan, M. J., Levine, T. R., Shearman, S. M., Lee, S. Y., Park, C.-Y., \& Kiyomiya, T. (2005). A multimethod multitrait validity assessment of self-construal in Japan, Korea, and the United States. Human Communication Research, 31, 33-59.

Brewer, M. B., \& Gardner, W. (1996). Who is this "we"? Levels of collective identity and self-representations. Journal of Personality and Social Psychology, 71, 83-93.

Brown, R. P., \& Pinel, E. C. (2003). Stigma on my mind: Individual differences in the experience of stereotype threat. Journal of Experimental Social Psychology, 39, 626-633.

Cadinu, M., Maass, A., Rosabianca, A., \& Kiesner, J. (2005). Why do women underperform under stereotype threat? Evidence for the role of negative thinking. Psychological Science, 16, 572-578. 
Carver, C. S., \& Scheier, M. F. (1987). The blind men and the elephant: Selective examination of he public-private literature gives rise to a faulty perception. Journal of Personality, 55, 525-541.

Clogg, C. C., Petkova, E., \& Haritou, A. (1995). Statistical methods for comparing regression coefficients between models. American Journal of Sociology, 100, 1261-1293.

Cohen, G. L., \& Garcia, J. (2005). "I am us": Negative stereotypes as collective threats. Journal of Personality and Social Psychology, $89,566-582$.

Croizet, J.-C., Després, G., Gauzins, M.-E., Huguet, P., Leyens, J.-P., \& Méot, A. (2004). Stereotype threat undermines intellectual performance by triggering a disruptive mental load. Personality and Social Psychology Bulletin, 30, 721-731.

Darke, S. (1988). Effects of anxiety on inferential reasoning task performance. Journal of Personality and Social Psychology, 55, 499-505.

Davies, P. G., Spencer, S. J., Quinn, D. M., \& Gerhardstein, R. (2002). Consuming images: How television commercials that elicit stereotype threat can restrain women academically and professionally. Personality and Social Psychology Bulletin, 28, 1613-1628.

Eysenck, M. W., \& Calvo, M. G. (1992). Anxiety and performance: The processing efficiency theory. Cognition and Emotion, 6, 409-434.

Grace, S. L., \& Cramer, K. L. (2003). The elusive nature of self-measurement: The self-construal scale versus the twenty statements test. Journal of Social Psychology, 143, 649-668.

Huguet, P., \& Régner, I. (2007). Stereotype threat among school girls in quasi-ordinary classroom circumstances. Journal of Educational Psychology, 99, 545-560.

Jäger, A. O., \& Althoff, K. (1983). Der WILDE-Intelligenz-Test (WIT). [The WILDE Intelligence Test (WIT)]. Göttingen: Hogrefe.

Keller, J. (2002). Blatant stereotype threat and women's math performance: Self-handicapping as a strategic means to cope with obtrusive negative performance expectations. Sex Roles, 47, 193-198.

Keller, J. (2006). Test instructions involving punishments for mistakes augment disrupting effects of negative stereotypic expectancies on women's math and spatial performance: A self-regulatory perspective. Manuscript submitted for publication.

Keller, J. (2007). Stereotype threat in classroom settings: The interactive effect of domain identification, task difficulty, and stereotype threat on female students' math performance. British Journal of Educational Psychology, 77, 323-338.

Keller, J., \& Bless, H. (in press-a). Communicating positive or negative stereotypic expectancies: The interplay of stereotype threat and regulatory focus. In Y. Kashima, K. Fiedler, \& P. Freytag (Eds.), Stereotype dynamics: Language-based approaches to stereotype formation, maintenance, and transformation. Mahwah, NJ: Erlbaum.

Keller, J., \& Bless, H. (in press-b). When positive and negative expectancies disrupt performance: Regulatory focus as a catalyst. European Journal of Social Psychology.

Keller, J., \& Molix, L. (in press). When women can't do math: The interplay of self-construal, group identification, and stereotypic performance standards. Journal of Experimental Social Psychology.

Kemmelmeier, M., \& Oyserman, D. (2001). The ups and downs of thinking about a successful other: Self-construals and the consequences of social comparisons. European Journal of Social Psychology, 31, 311-320.

Lord, C. G., \& Saenz, D. S. (1985). Memory deficits and memory surfeits: Differential cognitive consequences of tokenism for tokens and observers. Journal of Personality and Social Psychology, 49, 918-926.

MacKinnon, D. P., Lockwood, C. M., Hoffman, J. M., West, S. G., \& Sheets, V. (2002). A comparison of methods to test mediation and other intervening variable effects. Psychological Methods, 7, 83-104.

Markus, H. R., \& Kitayama, S. (1991). Culture and the self: Implications for cognition, emotion, and motivation. Psychological Review, 98, 224-253.

Martens, A., Johns, M., Greenberg, J., \& Schimel, J. (2006). Combating stereotype threat: The effect of self-affirmation on women's intellectual performance. Journal of Experimental Social Psychology, 42, 236-243.

Marx, D. M., \& Stapel, D. A. (2006). Distinguishing stereotype threat from priming effects: On the role of the social self and threat-based concerns. Journal of Personality and Social Psychology, 91, 243-254.

Marx, D. M., Stapel, D. A., \& Muller, D. (2005). We can do it: The interplay of construal orientation and social comparison under threat. Journal of Personality and Social Psychology, 88, 432-446.

McGlone, M. S., \& Aronson, J. (2006). Stereotype threat, identity salience, and spatial reasoning. Journal of Applied Developmental Psychology, 27, 486-493.

Moè, A., \& Pazzaglia, F. (2007). Following the instructions! Effects of gender beliefs in mental rotation. Learning and Individual Differences, 16, 369-377.

Mor, N., \& Winquist, J. (2002). Self-focused attention and negative affect: A meta-analysis. Psychological Bulletin, 128, $638-662$.

Murphy, M. C., Steele, C. M., \& Gross, J. J. (2007). Signaling threat: How situational cues affect women in math, science, and engineering settings. Psychological Science, 18, 879-885.

National Science Foundation. (1996). Women, minorities, and persons with disabilities in science and engineering: 1996 (NFS Publication 96-311). Arlington, VA.

O'Brien, L., \& Crandall, C. S. (2003). Stereotype threat and arousal: Effects on women's math performance. Personality and Social Psychology Bulletin, 29, 782-789.

Pronin, E., Steele, C. M., \& Ross, L. (2004). Identity bifurcation in response to stereotype threat: Women and mathematics. Journal of Experimental Social Psychology, 40, 152-168.

Purdie-Vaughns, V., Steele, C. M., Davies, P. G., Ditlmann, R., \& Crosby, J. R. (2006). Social identity contingencies: How diversity cues signal threat or safety for African-Americans' in mainstream institutions. Manuscript submitted for publication. 
Quinn, D. M., \& Spencer, S. J. (2001). The interference of stereotype threat with women's generation of mathematical problem-solving strategies. Journal of Social Issues, 57, 55-71.

Sackett, P. R., DuBois, C. L. Z., \& Noe, A. W. (1991). Tokenism in performance evaluation: The effects of work group representation on male-female and White-Black differences in performance ratings. Journal of Applied Psychology, 76, $263-267$.

Sato, T., \& Cameron, J. E. (1999). The relationship between collective self-esteem and self-construal in Japan and Canada. Journal of Social Psychology, 139, 426-443.

Schmader, T., \& Johns, M. (2003). Converging evidence that stereotype threat reduces working memory capacity. Journal of Personality and Social Psychology, 85, 440-452.

Sekaquaptewa, D., \& Thompson, M. (2002). The differential effects of solo status on members of high- and low-status groups. Personality and Social Psychology Bulletin, 28, 694-707.

Sekaquaptewa, D., \& Thompson, M. (2003). Solo status, stereotype threat, and performance expectancies: Their effects on women's performance. Journal of Experimental Social Psychology, 39, 68-74.

Sekaquaptewa, D., Waldman, A., \& Thompson, M. (2007). Solo status and self-construal: Being distinctive influences racial identity and performance apprehension in African American women. Cultural Diversity and Ethnic Minority Psychology, 13, $321-327$.

Sharps, M. J., Welton, A. L., \& Price, J. L. (1993). Gender and task in the determination of spatial cognitive performance. Psychology of Women Quarterly, 17, 71-83.

Singelis, T. M. (1994). The measurement of independent and interdependent self-construals. Personality and Social Psychology Bulletin, 20, 580-591.

Spencer, S. J., Steele, C. M., \& Quinn, D. M. (1999). Stereotype threat and women's math performance. Journal of Experimental Social Psychology, 35, 4-28.

Steele, C. M., \& Aronson, J. (1995). Stereotype threat and the intellectual test performance of African Americans. Journal of Personality and Social Psychology, 69, 797-811.

Steele, C. M., Spencer, S. J., \& Aronson, J. (2002). Contending with group image: The psychology of stereotype and social identity threat. In M. P. Zanna (Ed.), Advances in experimental social psychology (Vol. 34, pp. 379-440). San Diego, CA: Academic Press.

Stone, J. (2002). Battling doubt by avoiding practice: The effects of stereotype threat on self-handicapping in White athletes. Personality and Social Psychology Bulletin, 28, 1667-1678.

Thompson, M., \& Sekaquaptewa, D. (2002). When being different is detrimental: Solo status and the performance of women and racial minorities. Analyses of Social Issues and Public Policy, 2, 183-203.

Wheeler, S. C., \& Petty, R. E. (2001). The effects of stereotype activation on behavior: A review of possible mechanisms. Psychological Bulletin, 127, 797-826. 